\title{
Association of Minimum Inhibitory Concentration Cluster Patterns with Dairy Management Practices for Environmental Bacteria Isolated from Bulk Tank Milk*
}

\author{
J. H. Kirk, ${ }^{1}$ B. McCowan, ${ }^{2}$ E. R. Atwill, ${ }^{1,2}$ K. S. Glenn, ${ }^{2}$ G. E. Higginbotham, ${ }^{3}$ \\ C. A. Collar, ${ }^{4}$ A. Castillo, ${ }^{5}$ B. A. Reed, ${ }^{6}$ N. G. Peterson, ${ }^{7}$ and J. S. Cullor ${ }^{2}$ \\ ${ }^{1}$ Veterinary Medicine Extension, and \\ 2Department of Population Health and Reproduction, School of Veterinary Medicine, \\ University of California Davis, Tulare 93274 \\ ${ }^{3}$ University of California Cooperative Extension, Fresno and Madera Counties, Fresno 93702 \\ ${ }^{4}$ University of California Cooperative Extension, Kings County, Hanford 93230 \\ ${ }^{5}$ University of California Cooperative Extension, Merced County, Merced 95340 \\ 6University of California Cooperative Extension, Glenn County, Orland 95963 \\ ${ }^{7}$ University of California Cooperative Extension, San Bernardino County, San Bernardino 92415
}

\begin{abstract}
Environmental bacteria have emerged over the past few years to become significant causes of mastitis. Bacteria in this group are often reported by practicing veterinarians to be increasingly resistant to intramammary therapy and responsible for elevated bulk tank somatic cell counts. The purpose of this study was to determine the extent of association of the minimum inhibitory concentrations for selected antimicrobial agents with environmental bacteria isolated from bulk tank milk on California dairies and their housing facilities, husbandry practices, and antimicrobic-use strategies. Bulk tank milk samples were collected from 2 dairy cooperatives that had their milk cultured at the Milk Quality Laboratory, University of California Davis, Veterinary Medicine Teaching and Research Center in Tulare, CA. Samples were collected from July 2001 through March 2002 on 88 d; and 404 environmental bacteria isolated from 93 dairies were found. Minimum inhibitory concentrations were determined on 337 of the isolates for 10 antimicrobial agents. Cluster analysis was performed on the minimum inhibitory concentration values for each organism, and 4 antimicrobial clusters with varying degrees of resistance were found.

A 69-question survey questionnaire was completed on-farm for 49 of the 73 dairies that had at least 3 environmental bacterial isolates. The questionnaire sought information on housing facilities, milking management, mastitis prevention, antimicrobial usage
\end{abstract}

Received September 13, 2004.

Accepted May 5, 2005.

Corresponding author: E. R. Atwill; e-mail: ratwill@vmtrc. ucdavis.edu.

*Funding sources: USDA Animal Health Formula Funds, California Dairy Research Foundation, and Pfizer Animal Health. strategies, and owner/veterinary involvement in disease control and prevention. Multinomial logistic regression analysis found significant associations between the antimicrobial agent-resistance cluster groups and some of the housing and bedding practices, failure to dry udders before milking, and antimicrobial treatment of nonmastitis conditions. No association was noted for antimicrobial agent treatment of mastitis and the resistance cluster patterns.

(Key words: minimum inhibitory concentration, cluster pattern, environmental bacteria, bulk tank milk)

Abbreviation key: $\mathbf{M I C}_{\mathbf{9 0}}=$ MIC for $90 \%$ of isolates tested, MQL = Milk Quality Laboratory, $\mathbf{R R}=$ relative risk.

\section{INTRODUCTION}

Mastitis remains an economically significant disease of dairy cows (Fetrow et al., 2000). The major portion of the economic loss is due to reduced milk production in cows with subclinical mastitis (Ruegg, 2003). Grampositive bacteria such as Staphylococcus and Streptococcus species are responsible for much of this production loss. The influence of the contagious portion of these gram-positive bacteria has been markedly reduced (Hillerton and Berry, 2003; Hogan and Smith, 2003). Contagious mastitis pathogens are those that are transmitted primarily during milking from infected cow to susceptible cows. Mastitis caused by the environmental mastitis pathogens such as the coliforms and noncontagious Streptococcus species appeared to have become more important (Morin et al., 2001a). These environmental mastitis pathogens generally infect cows from environmental sites in the housing areas in between the milking periods. The negative impact of environmental bacteria has previously been reported 
(Hogan et al., 1989; Schukken et al., 1989; Gonzalez et al., 1990).

In California and some other western states, the socalled environmental Streptococcus species have emerged over the past few years to become significant causes of mastitis. Bacteria in this group are often reported by practicing veterinarians to be increasingly resistant to intramammary therapy and responsible for elevated bulk tank SCC. This has been particularly noticeable in dairy herds with low prevalence of contagious mastitis pathogens based on routine bulk tank culturing. In these herds, the bulk tank SCC that previously were consistently below 250,000 cells/mL may now exceed 350,000 cells $/ \mathrm{mL}$ in some cases.

The purpose of this study was to determine the extent of association between the MIC values for selected antimicrobial agents analyzed for environmental bacteria isolated from bulk tank milk and the housing facilities, husbandry practices, and antimicrobial agent usage strategies used on the dairies.

\section{MATERIALS AND METHODS}

\section{Bacterial Nomenclature}

For the purposes of this study, the environmental bacteria would include Streptococcus species other than Streptococcus agalactiae, Enterococcus spp., Aerococcus spp., and Lactococcus spp. The terms "environmental strep" or "e-streps" is often used by veterinary practitioners for this group of bacteria. The term "environmental Streptococcus species" in this report will be reserved for only those bacterial isolates in the genus Streptococcus. The term "non-Streptococcus species, environmental bacteria" shall be used to refer to the $E n$ terococcus spp., Aerococcus spp., and Lactococcus spp.

\section{Sampling Method}

Bulk tank milk samples from 2 large Central Valley California dairy cooperatives were cultured by the Milk Quality Laboratory (MQL) at the University of California Davis, Veterinary Medical Teaching and Research Center in Tulare, CA. The bulk tank milk samples from the cooperative dairies are submitted monthly to the MQL for bacterial and mycoplasmal screening. Initially in July 2001, milk samples from about 400 dairies were screened for environmental bacteria as they were submitted to the MQL. Dairies with bulk tank milk samples containing a single colony or more of at least one environmental bacterium on the initial screening were resampled, whereas those without an environmental bacterium on the initial sampling were dropped from the study. Sampling continued until March 2002. During this 9-mo period, as bulk tank milk samples arrived at the MQL, an attempt was made to reculture bulk tank milk samples from all dairies that had previously contained environmental bacteria. However, due to the MQL caseload, it was not possible to locate each specific dairy each time bulk milk samples arrived.

\section{Bacteriology}

Presumptive identification of environmental bacteria was made using standard National Mastitis Councilrecommended culture procedures including colony characteristics on blood agar, CAMP reaction, gram staining, and catalase testing (Hogan et al., 1999). Environmental bacteria were stored in trypticase soy broth (Hardy Diagnostics, Santa Maria, CA) with 10\% glycerin at $-80^{\circ} \mathrm{C}$ for further analysis. Later, a definitive identification was made on each isolate using the API 20 Streptococcus system, a commercially available, biochemical identification system (BioMerieux-Vitek Inc., Hazelwood, MO). In some cases, it was not possible to identify the bacterium beyond the genus level with API 20 Streptococcus system.

\section{Antimicrobial Agents}

The antimicrobial agents were selected to represent the common therapeutic agents used to treat bovine mastitis with intramammary infusion on California dairies. Additional agents of interest to the supporting organization were also used despite not being labeled for intramammary use in lactating dairy cows.

\section{MIC}

An automated, broth microdilution method was used to determine the MIC. The MIC analyses were performed according to the method described by National Committee for Clinical Laboratory Standards (NCCLS, 2000). Antimicrobial agents used for the MIC determination were lincomycin, neomycin, ampicillin, oxacillin, cephapirin, ceftiofur, penicillin+novobiocin, erythromycin, and pirlimycin. Penicillin and novobiocin were tested in combination. Each bacterial isolate was tested for each antimicrobial agent. For each antimicrobial agent, $50 \mu \mathrm{L}$ of bacteria was placed in serial 2 -fold dilution ranging from 0.06 to $64.0 \mu \mathrm{g} / \mathrm{mL}$ for each antimicrobial agent. American Type Culture Collection Staphylococcus aureus 29213, Enterococcus faecalis 29212, Escherichia coli 25922, and Pseudomonas aeruginosa 27853 reference strains, as required by the $\mathrm{Na}$ tional Committee for Clinical Laboratory Standards (NCCLS, 2000), were used at the beginning of each MIC determination for quality control. 


\section{Survey Questionnaire}

A face-to-face, on-dairy questionnaire was conducted by the primary author (JHK) and the University of California Cooperative Extension dairy advisors. The same questionnaire was used on each dairy. The primary author visited several dairies with each advisor for training purposes. The 11-page survey instrument covered topics on housing style (15 questions), bedding types (9 questions), bedding management (10 questions), antimicrobial agent usage in calves (5 questions) and cows (10 questions) for nonmastitis conditions, antimicrobial agent use for dry-cow treatment (6 questions) as well as mild ( 7 questions) and severe (15 questions) clinical mastitis cases, calf-raising methods (19 questions), milking technique and milking hygiene (16 questions), and owner/herdsmen/veterinary involvement in prevention, control, and treatment of mastitis (13 questions). Questions on antimicrobial use described antimicrobial types, label or extra-label use, commercial or dairy origin, current use, previous use, and existence of written protocols and records. The questionnaire took approximately 45 minutes to complete on the dairy.

\section{Cluster Analysis}

The actual MIC values for each bacterium and each of the 10 antimicrobial agents were the dependent variables used to conduct the model-based cluster analysis using the MCLUST extension to S-PLUS statistical software (Insightful Corp., Seattle, WA) to categorize patterns of antimicrobial agent resistance into resistance groups or clusters (Farley and Raftery, 2000, 2002). The advantage of using MCLUST over other traditional clustering methods is that one can cluster the data using 10 different models representing differences in cluster distribution, volume, shape, and orientation (Farley and Raftery, 2002). In this clustering strategy, the model and number of clusters are simultaneously selected by maximizing the Bayesian information criterion (Farley and Raftery, 2000, 2002) as opposed to subjective, nonstatistical measures.

\section{Statistical Analyses}

The association between environmental bacteria in the bulk tank exhibiting one of the various clustered patterns of antimicrobial resistance and the facilities, antimicrobial agent use, and animal management practices for the dairies were tested using multinomial logistic regression. For this model, the set of clusters for antimicrobial agent resistance generated by the MCLUST method functioned as the outcome variable, with bacteria exhibiting antimicrobial agent resistance
Table 1. Distribution of environmental bacterial isolates by dairies from bulk tank milk samples from California dairies.

\begin{tabular}{lrr}
\hline Bacterial isolates & $\begin{array}{l}\text { No. isolated } \\
(\%)\end{array}$ & $\begin{array}{l}\text { MIC } \\
\text { determination }\end{array}$ \\
\hline Streptococcus uberis & $161(42.4)$ & $139(41.2)$ \\
Streptococcus dysgalactiae & $62(16.3)$ & $55(16.3)$ \\
Enterococcus faecium & $40(10.5)$ & $36(10.7)$ \\
Aerococcus viridans & $24(6.3)$ & $20(5.9)$ \\
Lactococcus lactis lactis & $22(5.8)$ & $21(6.2)$ \\
Enterococcus spp. & $21(5.5)$ & $19(5.6)$ \\
Streptococcus spp. & $20(5.2)$ & $17(5.0)$ \\
Streptococcus bovis & $16(4.2)$ & $16(4.7)$ \\
Enterococcus faecalis & $10(2.6)$ & $10(3.0)$ \\
Other & $4(0.1)$ & $4(0.1)$ \\
Total & 378 & 337 \\
\hline
\end{tabular}

traits consistent with cluster 1 (minimal identifiable resistance) as the referent outcome variable. Explanatory variables were the various antimicrobial agent treatment policies in place on the dairies and the variety of management practices described in the survey questionnaire. Models were constructed using a forward stepping algorithm, with the $P$-value set a 0.01 based on a likelihood ratio test for inclusion and retention in the model.

\section{RESULTS AND DISCUSSION}

The focus of our study was the environmental Streptococcus spp., Enterococcus spp., Aerococcus spp., and Lactococcus spp. commonly referred to by many veterinarians, milk quality laboratories, and others as the "environmental streps" (Morin et al., 2001b; Hillerton and Berry, 2003). The environmental bacteria isolated from bulk tank milk samples in this study (Table 1) are similar to those previously reported from bulk tank samples (Wolfgang et al., 2001) and clinical cases of mastitis (Rossitto et al., 2002; Hillerton and Berry, 2003). Therefore, it is reasonable to conclude that these environmental bacteria represent potential mastitis pathogens.

Bulk tank milk samples were collected at the MQL on 88 d between July 2001 and March 2002. Environmental bacteria were found in the bulk tank milk of 93 dairies. Using the API 20 technique, 378 isolates were identified to species in 4 genera, and 26 could only be differentiated to genera (Table 1).

Streptococcus uberis (42.4\%) and Streptococcus dysgalactiae (16.3\%) were the most commonly isolated environmental Streptococcus species in this study (Table 1) and this is consistent with other reports (Gonzalez et al., 1990; Rossitto et al., 2002; Hillerton and Berry, 2003). Enterococcus faecium $(10.5 \%)$ was also frequently found. The Streptococcus spp. were the most frequently isolated (68.8\%), whereas Enterococcus spp. 
Table 2. Distribution of MIC values by antimicrobial agent dilution for Streptococcus dysgalactiae isolates from bulk tank milk samples collected from California dairies with environmental bacteria in the bulk tank milk. ${ }^{1}$

\begin{tabular}{lcccccccccccc}
\hline & \multicolumn{10}{c}{ Antimicrobial agent dilution, $\mu \mathrm{g} / \mathrm{mL}$} \\
\cline { 2 - 13 } Agent & 0.06 & 0.12 & 0.25 & 0.5 & 1.0 & 2.0 & 4.0 & 8.0 & 16.0 & 32.0 & 64.0 & $>64.0$ \\
\hline Ampicillin & $49^{2}$ & $5^{3}$ & 1 & 0 & 0 & 0 & 0 & 0 & 0 & 0 & 0 & 0 \\
Oxacillin & $45^{2}$ & $5^{3}$ & 2 & 0 & 2 & 0 & 1 & 0 & 0 & 0 & 0 & 0 \\
Cephapirin & 4 & $46^{2}$ & $3^{3}$ & 0 & 1 & 0 & 1 & 0 & 0 & 0 & 0 & 0 \\
Penicillin+novobiocin & $51^{2}$ & $3^{3}$ & 0 & 0 & 0 & 0 & 0 & 0 & 0 & 0 & 0 & 0 \\
Erythromycin & $50^{2}$ & $1^{3}$ & 2 & 1 & 0 & 0 & 0 & 0 & 0 & 0 & 0 & 1 \\
Pirlimycin & $43^{2}$ & 5 & 1 & 0 & 0 & $2^{3}$ & 2 & 1 & 0 & 0 & 0 & 1 \\
Lincomycin+neomycin & 2 & 23 & $10^{2}$ & 2 & 7 & 4 & 0 & 1 & 0 & 0 & $6^{3}$ & 0 \\
Ceftiofur & $51^{2,3}$ & 2 & 0 & 0 & 1 & 1 & 0 & 0 & 0 & 0 & 0 & 0 \\
\hline
\end{tabular}

${ }^{1}$ Values indicate no. of isolates with MIC at the dilution indicated.

${ }^{2} \mathrm{MIC}_{50}=\mathrm{MIC}$ for $50 \%$ of isolates tested.

${ }^{3} \mathrm{MIC}_{90}=$ MIC for $90 \%$ of isolates tested.

accounted for $18.1 \%$, Aerococcus spp. for $6.3 \%$, and Lactococcus spp. for $5.8 \%$.

Minimum inhibitory concentrations were determined on 337 of the 378 bacterial isolates. The isolates lost in storage represented $13.7 \%$ of Strep. uberis isolates; $11.3 \%$ of Strep. dysgalactiae; $10 \%$ of E. faecium; and $16.7 \%$ of Aerococcus spp. The distribution of MIC values for selected bacteria is shown in Tables 2 to 7. The MIC range for our isolates is similar to that previously reported for ampicillin, cephapirin, penicillin+novobiocin, erythromycin, and pirlimycin with Strep. dysgalactiae and E. faecalis. However, the MIC range for Strep. uberis and E. faecium was extended for these antimicrobial agents compared with previous reports indicating a greater degree of resistance (Constable and Morin, 2003; Erskine et al., 2003). This supports the suggestion that different populations of bacteria with varying microbial susceptibilities exist in different areas of the US (Zadoks et al., 2001; Erskine et al., 2003). Hillerton and Berry (2003) suggested that local individual farm factors may also be responsible for the variations.

The MIC for $90 \%$ of the isolates tested $\left(\mathbf{M I C}_{\mathbf{9 0}}\right.$ ) for Strep. dysgalactiae with the 6 agents available as intramammary infusion products was $0.25 \mu \mathrm{g} / \mathrm{mL}$ or less with the exception of pirlimycin at $2.0 \mu \mathrm{g} / \mathrm{mL}$ (Table 2). For noninfusion products, the $\mathrm{MIC}_{90}$ was similar for ceftiofur but higher for lincomycin/neomycin at $64 \mu \mathrm{g} /$ $\mathrm{mL}$. For the infusion products, the $\mathrm{MIC}_{90}$ for Strep. uberis was $2.0 \mu \mathrm{g} / \mathrm{mL}$ or less except for erythromycin and pirlimycin that were $64 \mu \mathrm{g} / \mathrm{mL}$ or greater (Table 3). For Strep. bovis, the $\mathrm{MIC}_{90}$ values were less than 4.0 $\mu \mathrm{g} / \mathrm{mL}$, with the exception of the lincomycin/neomycin combination at $64.0 \mu \mathrm{g} / \mathrm{mL}$. The $\mathrm{MIC}_{90}$ for Streptococcus spp. was variable at $0.06 \mu \mathrm{g} / \mathrm{mL}$ for ampicillin and the penicillin+novobiocin combination but greater than 2.0 $\mu \mathrm{g} / \mathrm{mL}$ for other products (Table 4). The $\mathrm{MIC}_{90}$ for $E$. faecalis was greater than $0.5 \mu \mathrm{g} / \mathrm{mL}$ and less than 32 $\mu \mathrm{g} / \mathrm{mL}$ (Table 5). For E. faecium, the $\mathrm{MIC}_{90}$ was greater than $0.5 \mu \mathrm{g} / \mathrm{mL}$ for all agents tested (Table 6). The

Table 3. Distribution of MIC values by antimicrobial agent dilution for Streptococcus uberis isolates from bulk tank milk samples collected from California dairies with environmental bacteria in the bulk tank milk. ${ }^{1}$

\begin{tabular}{lcccccccccccc}
\hline & \multicolumn{10}{c}{ Antimicrobial agent dilution, $\mu \mathrm{g} / \mathrm{mL}$} \\
\cline { 2 - 15 } Agent & 0.06 & 0.12 & 0.25 & 0.5 & 1.0 & 2.0 & 4.0 & 8.0 & 16.0 & 32.0 & 64.0 & $>64.0$ \\
\hline Ampicillin & 28 & $53^{2}$ & $54^{3}$ & 4 & 0 & 0 & 0 & 0 & 0 & 0 & 0 & 0 \\
Oxacillin & 4 & 7 & 7 & 11 & $60^{2}$ & $43^{3}$ & 3 & 4 & 0 & 0 & 0 & 0 \\
Cephapirin & 2 & 10 & 25 & $52^{2}$ & $42^{3}$ & 2 & 1 & 2 & 1 & 0 & 1 & 0 \\
Penicillin+novobiocin & 52 & $66^{2}$ & $17^{3}$ & 3 & 1 & 0 & 0 & 0 & 0 & 0 & 0 & 0 \\
Erythromycin & $80^{2}$ & 3 & 2 & 2 & 2 & 8 & 8 & 2 & 1 & 0 & 0 & $30^{3}$ \\
Pirlimycin & 62 & $11^{2}$ & 2 & 0 & 6 & 13 & 13 & 1 & 4 & 3 & $13^{3}$ & 11 \\
Lincomycin+neomycin & 21 & 24 & 4 & 1 & 4 & 15 & $7^{2}$ & 6 & 1 & 4 & $38^{3}$ & 14 \\
Ceftiofur & 31 & 6 & 14 & $44^{2}$ & $33^{3}$ & 3 & 2 & 2 & 0 & 0 & 0 & 0 \\
\hline
\end{tabular}

${ }^{1}$ Values indicate no. of isolates with MIC at the dilution indicated.

${ }^{2} \mathrm{MIC}_{50}=\mathrm{MIC}$ for $50 \%$ of isolates tested.

${ }^{3} \mathrm{MIC}_{90}=\mathrm{MIC}$ for $90 \%$ of isolates tested. 
Table 4. Distribution of MIC values by antimicrobial agent dilution for Streptococcus species isolates from bulk tank milk samples collected from California dairies with environmental bacteria in the bulk tank milk. ${ }^{1}$

\begin{tabular}{|c|c|c|c|c|c|c|c|c|c|c|c|c|}
\hline \multirow[b]{2}{*}{ Agent } & \multicolumn{12}{|c|}{ Antimicrobial agent dilution, $\mu \mathrm{g} / \mathrm{mL}$} \\
\hline & 0.06 & 0.12 & 0.25 & 0.5 & 1.0 & 2.0 & 4.0 & 8.0 & 16.0 & 32.0 & 64.0 & $>64.0$ \\
\hline Ampicillin & $17^{2,3}$ & 0 & 0 & 0 & 0 & 0 & 0 & 0 & 0 & 0 & 0 & 0 \\
\hline Oxacillin & $10^{2}$ & 1 & 4 & $2^{3}$ & 0 & 0 & 0 & 0 & 0 & 0 & 0 & 0 \\
\hline Cephapirin & 2 & $7^{2}$ & 5 & 1 & 0 & 0 & 0 & $2^{3}$ & 0 & 0 & 0 & 0 \\
\hline Penicillin+novobiocin & $17^{2,3}$ & 0 & 0 & 0 & 0 & 0 & 0 & 0 & 0 & 0 & 0 & 0 \\
\hline Erythromycin & $10^{2}$ & 0 & 1 & 0 & 1 & 1 & 2 & $1^{3}$ & 0 & 0 & 0 & 1 \\
\hline Pirlimycin & $13^{2}$ & 0 & 0 & 1 & 0 & 0 & 0 & 0 & 0 & 1 & $1^{3}$ & 1 \\
\hline Lincomycin+neomycin & 0 & 1 & 1 & 0 & 0 & $7^{2}$ & 4 & 0 & 2 & $1^{3}$ & 0 & 1 \\
\hline Ceftiofur & $12^{2}$ & 2 & 1 & 0 & 0 & 0 & $1^{3}$ & 1 & 0 & 0 & 0 & 0 \\
\hline
\end{tabular}

${ }^{1}$ Values indicate no. of isolates with MIC at the dilution indicated.

${ }^{2} \mathrm{MIC}_{50}=\mathrm{MIC}$ for $50 \%$ of isolates tested.

${ }^{3} \mathrm{MIC}_{90}=\mathrm{MIC}$ for $90 \%$ of isolates tested.

$\mathrm{MIC}_{90}$ for the Enterococcus spp. was $1.0 \mu \mathrm{g} / \mathrm{mL}$ or greater (Table 7). Based on our MIC data, Strep. dysgalactiae would have an overall lower $\mathrm{MIC}_{90}$ for these antimicrobial agents, whereas $E$. faecalis would have a higher $\mathrm{MIC}_{90}$, with Strep. uberis and E. faecium at an intermediate range.

There were also sufficient bacterial isolates of Aerococcus and Lactococcus to calculate a MIC value. The $\mathrm{MIC}_{90}$ values for Aerococcus were diverse, with ampicillin, penicillin+novobiocin, and pirlimycin at less than $0.5 \mu \mathrm{g} / \mathrm{mL}$; however, the remaining antimicrobial agents were $8.0 \mu \mathrm{g} / \mathrm{mL}$ or greater. The $\mathrm{MIC}_{90}$ values for Lactococcus were $0.5 \mu \mathrm{g} / \mathrm{mL}$ or greater with erythromycin, pirlimycin, and lincomycin/neomycin being greater than $16 \mu \mathrm{g} / \mathrm{mL}$.

We chose to use MIC over other methods to estimate the extent of antimicrobial agent resistance as the MQL had previous experience with this method. Moreover, the MQL was experienced with the microdilution methods using the automated equipment for the MIC testing, which was available in our laboratory. Realizing that validated MIC breakpoints to determine microbial susceptibility (susceptible, intermediate, or resistant) were not available based on bovine mastitis trials (Constable and Morin, 2003; Erskine et al., 2003) at the time of this study, we used the actual MIC values to estimate the degree of resistance for each antimicrobial agent and bacteria. It should be noted that since the time of the study, MIC breakpoints based on bovine mastitis criteria have become available for ceftiofur, penicillin+novobiocin, and pirlimycin and could be utilized in future studies similar to this one.

Using the cluster analysis with the default settings for the EMclust command in MCLUST, we tested from 1 to 20 clusters and all 10 models on the MIC values. The Bayesian information criterion was then used to determine which was the best model and number of clusters. The best model was VEV with 4 clusters (Figure 1). This result had a mean clustering uncertainty of 0.05 and a median clustering uncertainty of 0.006 , which is very low, suggesting little overlap among the clusters (Farley and Raftery, 2000, 2002). Model VEV

Table 5. Distribution of MIC values by antimicrobial agent dilution for Enterococcus faecalis isolates from bulk tank milk samples collected from California dairies with environmental bacteria in the bulk tank milk. $^{1}$

Antimicrobial agent dilution, $\mu \mathrm{g} / \mathrm{mL}$

\begin{tabular}{|c|c|c|c|c|c|c|c|c|c|c|c|c|}
\hline \multirow[b]{2}{*}{ Agent } & & & & & & & & & & & & \\
\hline & 0.06 & 0.12 & 0.25 & 0.5 & 1.0 & 2.0 & 4.0 & 8.0 & 16.0 & 32.0 & 64.0 & $>64.0$ \\
\hline Ampicillin & 0 & 0 & 2 & $5^{2}$ & $3^{3}$ & 0 & 0 & 0 & 0 & 0 & 0 & 0 \\
\hline Oxacillin & 0 & 0 & 0 & 0 & 0 & 1 & 1 & 3 & $6^{2,3}$ & 0 & 0 & 0 \\
\hline Cephapirin & 0 & 0 & 0 & 0 & 0 & 0 & 1 & 3 & $2^{2}$ & $4^{3}$ & 0 & 0 \\
\hline Penicillin+novobiocin & 0 & 1 & 1 & 2 & $6^{2,3}$ & 0 & 0 & 0 & 0 & 0 & 0 & 0 \\
\hline Erythromycin & 3 & 0 & $5^{2}$ & $1^{3}$ & 1 & 0 & 0 & 0 & 0 & 0 & 0 & 0 \\
\hline Pirlimycin & 1 & 0 & 1 & 0 & $3^{2}$ & 1 & 1 & 0 & 1 & $1^{3}$ & 0 & 0 \\
\hline Lincomycin + neomycin & 0 & 0 & 0 & 0 & 0 & 0 & $5^{2}$ & $3^{3}$ & 1 & 0 & 0 & 0 \\
\hline Ceftiofur & 0 & 0 & 0 & 2 & 1 & $1^{2}$ & 0 & 0 & $3^{3}$ & 1 & 0 & 0 \\
\hline
\end{tabular}

${ }^{1}$ Values indicate no. of isolates with MIC at the dilution indicated.

${ }^{2} \mathrm{MIC}_{50}=\mathrm{MIC}$ for $50 \%$ of isolates tested.

${ }^{3} \mathrm{MIC}_{90}=\mathrm{MIC}$ for $90 \%$ of isolates tested. 
Table 6. Distribution of MIC values by antimicrobial agent dilution for Enterococcus faecium isolates from bulk tank milk samples collected from California dairies with environmental bacteria in the bulk tank milk. ${ }^{1}$

\begin{tabular}{llccccccccccc}
\hline & \multicolumn{10}{c}{ Antimicrobial agent dilution, $\mu \mathrm{g} / \mathrm{mL}$} \\
\cline { 2 - 13 } Agent & 0.06 & 0.12 & 0.25 & 0.5 & 1.0 & 2.0 & 4.0 & 8.0 & 16.0 & 32.0 & 64.0 & $>64.0$ \\
\hline Ampicillin & 1 & 5 & 3 & $14^{2}$ & 9 & $4^{2}$ & 0 & 0 & 0 & 0 & 0 & 0 \\
Oxacillin & 0 & 1 & 1 & 2 & 2 & 4 & $8^{2}$ & 9 & 3 & 1 & $5^{3}$ & 0 \\
Cephapirin & 0 & 0 & 1 & 1 & 0 & 2 & 4 & 2 & 3 & $11^{2}$ & $12^{3}$ & 0 \\
Penicillin+novobiocin & 2 & 6 & $20^{2}$ & $6^{3}$ & 2 & 0 & 0 & 0 & 0 & 0 & 0 & 0 \\
Erythromycin & 8 & 5 & 0 & 3 & $6^{2}$ & 8 & 2 & $2^{3}$ & 0 & 0 & 0 & 2 \\
Pirlimycin & 5 & 10 & 0 & 1 & $4^{2}$ & 2 & 3 & 7 & $1^{3}$ & 1 & 2 & 0 \\
Lincomycin+neomycin & 2 & 3 & 4 & 7 & 1 & 0 & $5^{2}$ & 5 & $6^{3}$ & 1 & 2 & 0 \\
Ceftiofur & 2 & 0 & 2 & 2 & 0 & 0 & 0 & 1 & 2 & 1 & $25^{2,3}$ & 0 \\
\hline
\end{tabular}

${ }^{1}$ Values indicate no. of isolates with MIC at the dilution indicated.

${ }^{2} \mathrm{MIC}_{50}=\mathrm{MIC}$ for $50 \%$ of isolates tested.

${ }^{3} \mathrm{MIC}_{90}=\mathrm{MIC}$ for $90 \%$ of isolates tested.

has an ellipsoidal distribution, variable volume, equal shape, and variable orientation.

Cluster analysis techniques have been used previously to describe patterns of antimicrobial agent resistance for livestock bacteria (Berge et al., 2003). In this previous study of calf fecal E. coli, 12 antimicrobial agents were subjected to cluster analysis. They found 14 patterns existed in this bacteria obtained from cohorts of 30 calves sampled on 6 dairies. In the cluster analysis, we used the actual MIC values determined for each antimicrobial agent and bacteria. Our analysis found 4 common clusters of susceptibility within the bacterial isolates from bulk tank milk from 44 dairies. The most common microbial susceptibility cluster pattern was found to be minimal or no resistance (44.1\%) and was found alone on a single dairy and in combination with more resistant clusters on 41 of the 44 dairies in the cluster analysis. This cluster included 77\% Streptococcus spp., 6\% Enterococcus spp., 6\% Aerococcus spp., and 9\% Lactococcus spp. (Table 8). One-half of the streptococcal isolates and $15 \%$ of the enterococcal isolates were in Cluster 1. The second most common cluster (22.7\%) demonstrated some degree of resistance to lincomycin and neomycin and was found on 7 dairies as the only resistant cluster and in combination with other resistant clusters on 20 of 44 dairies. This cluster included $90 \%$ Streptococcus spp. and only $4 \%$ Enterococcus spp. (Table 8). Of the streptococcal isolates, $30 \%$ had the Cluster 2 pattern of resistance. A third cluster (19.4\%) showed resistance to lincomycin, neomycin, erythromycin, and pirlimycin, and was found as a single resistant cluster on 6 dairies and with other resistant clusters on 19 of 44 dairies. This cluster pattern was made up of 68\% Streptococcus spp., $17 \%$ Enterococcus spp., and 15\% Lactococcus spp. (Table 8). The final cluster $(13.7 \%)$ had some resistance to ceftiofur, cephapirin, and oxacillin and was found as the only resistant cluster on 7 dairies and combination with other resistant clusters on 11 of 44 dairies. This cluster was made up of primarily Enterococcus spp. (86\%) and no streptococcal isolates (Table 8).

Table 7. Distribution of MIC values by antimicrobial agent dilution for Enterococcus species isolates from bulk tank milk samples collected from California dairies with environmental bacteria in the bulk tank milk. ${ }^{1}$

\begin{tabular}{lllllllllllll}
\hline & \multicolumn{10}{c}{ Antimicrobial agent dilution, $\mu \mathrm{g} / \mathrm{mL}$} \\
\cline { 2 - 13 } Agent & 0.06 & 0.12 & 0.25 & 0.5 & 1.0 & 2.0 & 4.0 & 8.0 & 16.0 & 32.0 & 64.0 & $>64.0$ \\
\hline Ampicillin & 2 & 1 & $6^{2}$ & 5 & $3^{3}$ & 0 & 0 & 0 & 0 & 0 & 0 & 0 \\
Oxacillin & 1 & 0 & 1 & 2 & 2 & 0 & $4^{2}$ & 3 & $3^{3}$ & 0 & 1 & 0 \\
Cephapirin & 1 & 0 & 1 & 1 & 1 & 2 & 1 & $4^{2}$ & 1 & 3 & $2^{3}$ & 0 \\
Penicillin+novobiocin & 2 & 5 & $4^{2}$ & 3 & $3^{3}$ & 0 & 0 & 0 & 0 & 0 & 0 & 0 \\
Erythromycin & 6 & 0 & 1 & $2^{2}$ & 3 & $4^{3}$ & 0 & 0 & 0 & 0 & 0 & 1 \\
Pirlimycin & 4 & 1 & 0 & 0 & $4^{2}$ & 2 & 1 & 1 & 0 & $3^{3}$ & 1 & 0 \\
Lincomycin+neomycin & 2 & 0 & 0 & 2 & 0 & 0 & $5^{2}$ & 6 & 0 & 0 & $2^{3}$ & 0 \\
Ceftiofur & 3 & 1 & 2 & $2^{2}$ & 1 & 0 & 3 & 0 & 2 & 1 & 0 & $2^{3}$ \\
\hline
\end{tabular}

${ }^{1}$ Values indicate no. of isolates with MIC at the dilution indicated.

${ }^{2} \mathrm{MIC}_{50}=\mathrm{MIC}$ for $50 \%$ of isolates tested.

${ }^{3} \mathrm{MIC}_{90}=\mathrm{MIC}$ for $90 \%$ of isolates tested. 


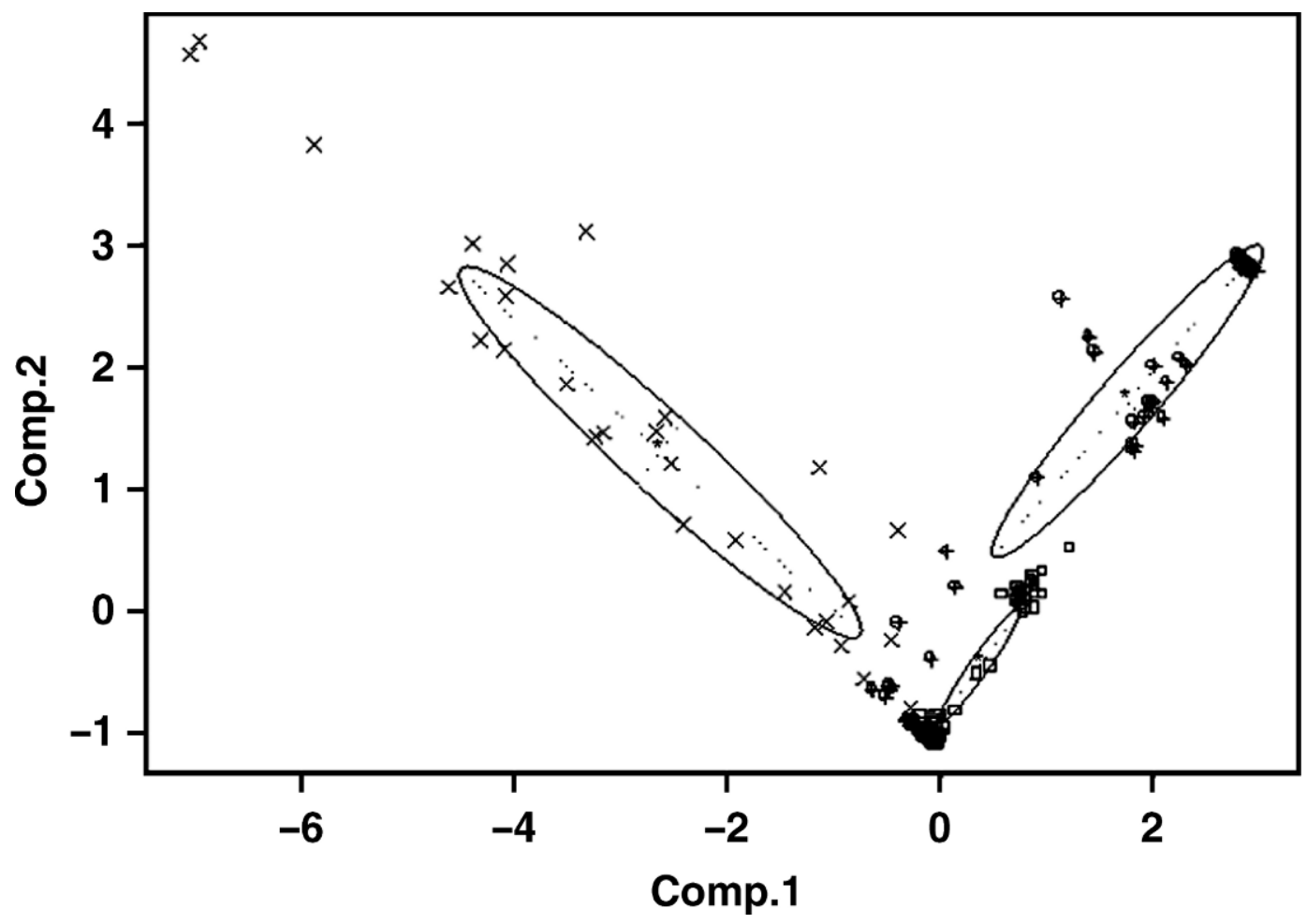

Figure 1. Distribution of the 4 clusters in 2-D space for the minimum inhibitory concentration data. The ellipsoids show the standard deviations for each cluster.

These clustering patterns may reflect properties of the bacteria themselves or characteristics of the antimicrobial agents that were used in the analysis. For example, more than half the Streptococcus spp. were in Cluster 1 and none are found in Cluster 4 (Table 8). The Enterococcus spp. were found in all 4 clusters but predominately in Cluster 4. Other genera have different cluster distributions (Table 8). With regard to the antimicrobial agents, the $\beta$-lactams (cephapirin and oxacillin) appeared in Cluster 4; the macrolides (erythromycin) and lincosamides (pirlimycin, lincomycin) appeared in Cluster 3. Thus, the clusters seem to represent anti- microbial agents with similar resistance mechanisms (Rossitto et al., 2002). However, neomycin, an aminoglycoside, also appeared in Cluster 3 with antimicrobics with a different mechanism of resistance.

The questionnaire was completed on 49 dairies of the 73 dairies for which there were at least 3 isolates with MIC determinations. Of the 22 dairies lost to followup, ownership had changed in 4 , the dairy advisors were unable to contact 8 dairies in their counties, and the remaining 10 dairies were located in areas no longer served by dairy advisors. Information on milking management, mastitis monitoring, alley cleaning, heat

Table 8. Distribution of antimicrobial agent resistance clusters ${ }^{1}$ for bacterial genera from bulk tank milk samples of California dairies.

\begin{tabular}{lcccc}
\hline Bacterial isolates & Cluster 1 & Cluster 2 & Cluster 3 & Cluster 4 \\
\hline Aerococcus & 6 & 2 & 0 & 2 \\
Enterococcus & 6 & 2 & 7 & 25 \\
Gamella & 0 & 1 & 0 & 0 \\
Lactococcus & 8 & 0 & 6 & 2 \\
Leuconostoc & 1 & 0 & 0 & 0 \\
Streptococcus & 72 & 43 & 28 & 29 \\
Total & 93 & 48 & 31 & 0 \\
\hline
\end{tabular}

\footnotetext{
${ }^{1}$ Cluster $1=$ no resistance; Cluster $2=$ resistance to lincomycin and neomycin; Cluster $3=$ resistance to lincomycin, neomycin, erythromycin, and pirlimycin; Cluster = resistance to ceftiofur, cephapirin, and oxacillin.
} 
Table 9. Housing, bedding types, grooming, and amendments used on California dairies $(\mathrm{n}=49)$.

\begin{tabular}{|c|c|c|c|}
\hline \multirow[b]{2}{*}{ Characteristic } & \multicolumn{3}{|c|}{ No. of cows $(\%)$} \\
\hline & Milking & Far-off & Close-up \\
\hline Freestalls & $24(49)$ & $6(12)$ & $5(10)$ \\
\hline \multicolumn{4}{|l|}{ Bedding type } \\
\hline Recycled manure & $23(96)$ & $6(100)$ & $5(100)$ \\
\hline Sand on mats & $1(4)$ & $0(0)$ & $0(0)$ \\
\hline \multicolumn{4}{|c|}{ Bedding replacement frequency } \\
\hline$<7 \mathrm{~d}$ & $10(42)$ & $3(50)$ & $2(40)$ \\
\hline 8 to $21 \mathrm{~d}$ & $4(17)$ & $0(0)$ & $2(40)$ \\
\hline As needed & $9(38)$ & $3(50)$ & $1(20)$ \\
\hline Seasonally & $1(4)$ & $0(0)$ & $0(0)$ \\
\hline \multicolumn{4}{|l|}{ Grooming frequency } \\
\hline$\leq 7 \mathrm{~d}$ & $20(82)$ & $5(83)$ & $5(100)$ \\
\hline$>7 \mathrm{~d}$ & 4 (18) & $1(17)$ & $0(0)$ \\
\hline \multicolumn{4}{|l|}{ Amendments used } \\
\hline Organic & $6(25)$ & $2(33)$ & $2(40)$ \\
\hline Inorganic & $5(21)$ & $1(17)$ & $1(20)$ \\
\hline None & $13(54)$ & $3(50)$ & $2(40)$ \\
\hline \multirow{2}{*}{\multicolumn{4}{|c|}{ Bedding type }} \\
\hline & & & \\
\hline Dirt and manure & $24(100)$ & $41(100)$ & $43(100)$ \\
\hline \multicolumn{4}{|c|}{ Bedding replacement frequency } \\
\hline As needed & $10(42)$ & $17(41)$ & $20(47)$ \\
\hline Seasonally & $14(58)$ & $24(59)$ & $21(53)$ \\
\hline \multicolumn{4}{|l|}{ Grooming frequency } \\
\hline$\leq 7 \mathrm{~d}$ & $2(8)$ & $2(5)$ & $2(5)$ \\
\hline 8 to 30 & $4(18)$ & $7(17)$ & $7(16)$ \\
\hline As needed & $5(21)$ & $14(34)$ & $15(35)$ \\
\hline Seasonally & $10(42)$ & $18(44)$ & $19(44)$ \\
\hline \multicolumn{4}{|l|}{ Amendments used } \\
\hline Organic & $3(13)$ & $4(10)$ & $9(21)$ \\
\hline Inorganic & $2(8)$ & $3(7)$ & $5(12)$ \\
\hline None & $19(79)$ & $34(83)$ & $29(67)$ \\
\hline Pasture & $1(2)$ & $0(0)$ & $1(2)$ \\
\hline
\end{tabular}

abatement, calf housing, owner involvement in daily mastitis prevention, and veterinary involvement in disease prevention were omitted as the analyses showed they were not significantly associated with antimicrobial susceptibility (Tables 9 to 11).

Results of the questionnaire indicated that the housing of milking cows on the study dairies was equally divided between free-stalls (24) and corrals (24) with one pasture dairy (Table 9). Most of the 24 free-stall dairies used recycled, stacked, or composted manure

Table 10. Types of antimicrobial agents used to treat nonmastitis conditions in calves and cows on California dairies $(n=49)$.

\begin{tabular}{lcc}
\hline & \multicolumn{2}{c}{ No. of animals $(\%)$} \\
\cline { 2 - 3 } Antimicrobial agent & Calves & Cows \\
\hline Ceftiofur & $15(31)$ & $39(80)$ \\
Tetracyclines & $14(29)$ & $17(35)$ \\
Penicillin & $13(27)$ & $28(57)$ \\
Florfenicol & $19(20)$ & $2(4)$ \\
Gentamicin & $6(12)$ & $0(0)$ \\
Tilmicosin & $5(10)$ & $0(0)$ \\
Others & $20(41)$ & $21(43)$ \\
\hline
\end{tabular}

Table 11. Types of antimicrobial agents used to treat clinical mastitis on California dairies $(\mathrm{n}=49)$.

\begin{tabular}{lrrr}
\hline & \multicolumn{3}{c}{ No. of cases (\%) } \\
\cline { 2 - 4 } Antimicrobial agent & \multicolumn{1}{c}{ Mild } & Severe \\
\hline Intramammary infusion & & \\
$\quad$ Cephalosporin & $28(57)$ & $14(29)$ \\
Pirlimycin & $19(39)$ & $9(18)$ \\
Amoxicillin & $5(10)$ & $2(4)$ \\
Cloxacillin & $4(8)$ & $3(6)$ \\
Others & $4(8)$ & $4(8)$ \\
None & $3(6)$ & $22(45)$ \\
Injectables & & \\
Ceftiofur & $7(14)$ & $7(14)$ \\
Tetracyclines & $5(10)$ & $13(27)$ \\
Penicillin & $5(10)$ & $5(10)$ \\
Others & $4(8)$ & $7(14)$ \\
None & $28(57)$ & $21(43)$ \\
\hline
\end{tabular}

for bedding, whereas the corrals were bedded with dirt and manure. Details for bedding management for milking cows (far-off or those cows recently ending their lactation), close-up or nonmilking cows within $3 \mathrm{wk}$ of calving, and those cows in the calving pens are shown in Table 9.

The dairies that raised their own calves (21/49) used 3 or more antimicrobial agents to treat calf-hood diseases and had not recently changed their antimicrobial agent use (Table 10). Thirteen antimicrobial agents were being used to treat calves. Many dairymen (21/49) did not know if extra-label doses were being used to treat their calves. Nineteen dairies sent their calves to be raised on calf ranches and had no information on antimicrobial agent treatments of their calves while off the home dairy.

Most of the dairies (34/49) were using at least 2 antimicrobial agents to treat nonmastitis conditions in mature cows (Table 10). Mostly penicillin was used in an extra-label manner. Often antimicrobial agents were used in combinations. On 32 dairies, the antimicrobial agents being used were prescribed by veterinarians.

For treatment of mild cases of mastitis, nearly $67 \%$ of the dairies used a single intramammary antimicrobial agent, and about $33 \%$ used 2 or more antimicrobial agents (Table 11). Three dairies did not use antimicrobial agents. Of the dairies using antimicrobial agents, $78 \%$ used them at label dose; the rest of the dairies used them at extra-label doses or were unaware of dose with respect to label directions. About $40 \%$ of the dairies used injectable antimicrobial agents to treat mild cases of mastitis. Of those that did use injectable antimicrobial agents, nearly $70 \%$ used extra-label doses. The use of injectable antimicrobial agents and extra-label dosages is common on California dairies without routine veterinary input into mastitis treatment strategies. 
Table 12. Management practices and antimicrobial agent treatment strategies on California dairies that are associated with the risk of being in Cluster 2 with antimicrobial resistance to lincomycin and neomycin rather than Cluster 1 with no antimicrobial resistance.

\begin{tabular}{llc}
\hline & $\begin{array}{l}\text { Relative } \\
\text { risk } \\
\text { ratio }\end{array}$ & $P$ value \\
Risk factor & & \\
\hline Use of organic amendments in the milking cow bedding materials & 1.0 & 0.06 \\
No & 2.61 & - \\
Yes & 1.0 & 0.01 \\
Use of organic amendments in far-off cow bedding materials & 3.07 & 0.01 \\
No & 1.04 & $<0.001$ \\
Yes & 0.95 & 0.001 \\
Days between grooming of milking cow bedding materials & 0.99 & - \\
Days between grooming of close-up cow bedding materials & 1.01 & 0.02 \\
Days between grooming of far-off cows bedding materials & & \\
Days between replacement of close-up cow bedding materials & 1.0 & - \\
Udders dried before milking machine attached & 4.40 & 0.04 \\
Yes & & 0.06 \\
No & 1.0 & 5.60 \\
Use of antimicrobial agent to treat milking cows for nonmastitis conditions & 4.95 & \\
None & & \\
Ceftiofur & & \\
Sulfadimethoxine & & \\
\hline
\end{tabular}

Twenty-two of the dairies did not treat severe cases of mastitis with intramammary antimicrobial agents and 7 of these sent the cows to market as soon as severe cases of mastitis were detected. On 29 dairies, the cows received nonantimicrobial agent supplemental treatments such as corticosteroids, hypertonic saline, banamine, or aspirin.

Most dairies (66\%) consulted their herd veterinarian for advice on selection of antimicrobial agents for treatment of calves and cows. However, $28 \%$ did not consult their veterinarian for advice or were uncertain about consultations (4\%). Antimicrobial agents were reported to be used in an extra-label manner on $31 \%$ of the dairies, and $56 \%$ of the managers reported that they did not use the agents in an extra-label manner. Some managers $(13 \%)$ were uncertain about extra-label use of antimicrobial agents in their animals.

The multinomial logistic regression analysis for association of housing facilities, husbandry practices, and antimicrobial agent use strategies used on the dairies with the resistance cluster patterns indicates that some dairy practices may modify the risk of the bacteria having antimicrobial agent resistance.

With respect to bedding practices, the use of organic amendments such as straw, rice hulls, gin trash, or almond hulls in the summer or winter increased the risk of bacteria being in Cluster 2 [relative risk $(\mathbf{R R})=$ 2.61, $P=0.06$; Table 12] or Cluster 3 (summer; $R R=$ $2.94, P=0.05$; winter, $R R=3.05, P=0.03$; Table 13 ) compared with Cluster 1, with a low degree of resistance. Clusters 2 and 3 largely comprise Streptococcus spp., which have often been reported to be associated with organic bedding materials such as straw (Hillerton and Berry, 2003). However, the use of inorganic amendments such as lime or fly ash in the milking cow bedding in the winter increased the risk of being Cluster $4(\mathrm{RR}=$ 4.06, $P=0.03$ ) compared with Cluster 1 (Table 14). Exposure to organic or inorganic bedding materials may then result in enhanced or restricted growth of the organisms or perhaps shifts in organism distributions to those more intrinsically resistant, thereby altering the antimicrobial agent resistance patterns.

In the housing for far-off dry cows, the use of amendments has different effects on risk of being in Cluster 2 or 3 compared with Cluster 1 . The use of organic amendments is associated with a greater risk of being in Cluster $2(\mathrm{RR}=3.07, P=0.01$; Table 12$)$, whereas organic, along with inorganic, amendments seem to reduce the risk of being in Cluster 3 (inorganic, $\mathrm{RR}=$ $0.34, P=0.08$; organic, $\mathrm{RR}=0.29, P=0.06$; Table 13 ). The addition of amendments was not associated with any increased risk in a resistance cluster for the closeup dry cows.

With regard to milking cows, the interval (in days) between grooming of the bedding materials was associated with a slight but significant increased risk of being Cluster 2 (RR = 1.04, $P=0.01$; Table 12$)$ compared with Cluster 1 with a low degree of resistance. The risk was much greater for being in Cluster $4(\mathrm{RR}=8.44, P<$ 0.001 , Table 14) compared with Cluster 1 with low resistance.

Far-off dry cows had a small but significant decrease in risk of being in Cluster $4(R R=0.87, P<0.001$; Table 14) compared with Cluster 1 with little resistance. In 
Table 13. Management practices and antimicrobial agent treatment strategies on California dairies that are associated with the risk of being in Cluster 3 with antimicrobial resistance to lincomycin, neomycin, erythromycin, and pirlimycin rather than Cluster 1 with no antimicrobial resistance.

\begin{tabular}{lll}
\hline & $\begin{array}{l}\text { Relative } \\
\text { risk } \\
\text { ratio }\end{array}$ & $P$ value \\
Risk factor & & \\
\hline Use of organic amendments in milking cow bedding materials & & 0.05 \\
$\quad$ Summer & 1.0 & - \\
$\quad$ No & 2.94 & 0.03 \\
$\quad$ Yes & 1.0 & - \\
Winter & 3.05 & 0.08 \\
$\quad$ No & & 0.06 \\
$\quad$ Yes & 1.0 & $<0.001$ \\
Use of amendments in far-off cow bedding materials & 0.34 & - \\
$\quad$ No & 0.29 & 0.06 \\
$\quad$ Inorganic & & 0.05 \\
$\quad$ Organic & 1.29 & \\
Days between replacement of close-up cow bedding materials & 1.0 & \\
Use of antimicrobial agents to treat cows for nonmastitis conditions & 5.50 & \\
$\quad$ None & 5.32 & \\
$\quad$ Penicillin & & \\
$\quad$ Ceftiofur & & \\
\hline
\end{tabular}

the close-up dry cows, a similar slight effect was seen with respect to being in Cluster $2(\mathrm{RR}=0.95, P=<0.001$; Table 12) compared with Cluster 1 ; however, the reduction of risk was greater for not being in Cluster $4(\mathrm{RR}=$ $0.12, P<0.001$; Table 14).

The number of days between replacement of bedding materials for the far-off dry cows slightly reduced the risk of being in Cluster $4(\mathrm{RR}=0.87, P<0.001$; Table 14) with some degree of antimicrobial resistance compared with being in Cluster 1 with a lower degree of resistance. Days between replacement of bedding materials for the close-up cows was associated with a small but significant increase in the risk of being in Cluster 3 $(\mathrm{RR}=1.29, P<0.001$; Table 13$)$ with some degree of resistance compared with being in Cluster 1 .

Bedding grooming practices had variable effects on clustering and most showed small but significant increases or decreases in risk compared with Cluster 1 . The exception was an increase in risk of being in Cluster 4 (Table 12) compared with Cluster 1 . Similar alter- ations in risk were seen with respect to the association of days between replacement of bedding materials and the risk of being in a cluster other than Cluster 1 .

The only milking procedure associated with antimicrobial agent resistance was drying udders before attaching the milk units. Not drying udders compared with drying was associated with an increased risk of being in Cluster $2(R R=4.40, P=0.02$; Table 12$)$ instead of Cluster 1.

No mastitis antimicrobial agent treatment practices were associated with an increased risk of being in Clusters 2,3 , or 4 compared with Cluster 1 with no resistance. However, the use of some antimicrobial agents for treatment of disease conditions other than mastitis was associated with an increased risk of being in one of the clusters with antimicrobial agent resistance. For instance, the use of ceftiofur was found to increase the risk of the bacteria of being in Cluster 2 (Table 12) compared with Cluster 1. Sulfadimethoxine $(R R=4.95$, $P=0.06$; Table 12) had a similar risk. The use of penicil-

Table 14. Management practices and antimicrobial agent treatment strategies on California dairies that are associated with the risk of being in Cluster 4 with antimicrobial resistance to ceftiofur, cephapirin, and oxacillin rather than Cluster 1 with no antimicrobial resistance.

\begin{tabular}{lcc}
\hline Risk factor & $\begin{array}{l}\text { Relative } \\
\text { risk } \\
\text { ratio }\end{array}$ & $P$ value \\
\hline Use of inorganic amendments in milking cow bedding materials in the winter & & \\
No & 1.0 & -0.03 \\
Yes & 4.06 & 8.44 \\
Days between grooming of milking cow bedding materials & 0.87 & $<0.001$ \\
Days between replacement of far-off cow bedding materials & 0.12 & $<0.001$ \\
Days between grooming of close-up cow bedding materials & \\
\hline
\end{tabular}


lin $(\mathrm{RR}=5.50, P=0.06$; Table 13$)$ and ceftiofur $(\mathrm{RR}=$ $5.32, P=0.05$; Table 13 ) were associated with an increased risk of the bacteria being in Cluster 3 compared with Cluster 1. No antimicrobial agents used for nonmastitic conditions were identified to have an increased risk of the bacterial isolate being in Cluster 4 compared with Cluster 1.

Milking cows with wet, soiled teats has been known to increase the risk of mastitis particularly from environmental bacteria. The finding of increased risk of being in Cluster 2, a predominant streptococcal cluster, compared with Cluster 1, when drying of udder is not done before milking may reflect the over-representation of Streptococcus spp. in the bulk tank milk samples.

Perhaps the most interesting association of the resistance clusters pertains to the use of antimicrobial agents. It might have been expected that antimicrobial agents used to treat mastitis would influence the clustering outcomes. However, this was not the case. The influential association was found with antimicrobial agent used for conditions other than mastitis. Some antimicrobial agents used for nonmastitis conditions increased the risk of being in Clusters 2 or 3 (Table 12 and 13), but not Cluster 4, compared with Cluster 1 . The reason for these changes in risk of resistance is not readily apparent.

\section{CONCLUSIONS}

The environmental bacteria isolated from bulk tank milk in this study are composed of Streptococcus spp., Enterococcus spp., Lactococcus spp., and Aerococcus spp. with a wide range of MIC values. By using cluster analysis, the bacteria were found to belong to 1 of 4 resistance clusters. The MIC resistance cluster groups were determined to be associated with several housing types, bedding types and management, milking practices, and antimicrobial use for nonmastitis conditions on the dairies. Mastitis antimicrobial treatment practices were not associated with the risk of being in a MIC resistance cluster pattern with increased risk of antimicrobial agent resistance.

\section{REFERENCES}

Berge, A. C. B., E. R. Atwill, and W. M. Sischo. 2003. Assessing antibiotic resistance in fecal Escherichia coli in young calves using cluster analysis techniques. Prev. Med. 61:91-102.

Constable, P. D., and D. E. Morin. 2003. Treatment of clinical mastitis using antimicrobial susceptibility profiles for treatment decisions. Vet. Clin. North Am. Food Anim. Pract. 19:139-155.
Erskine, R. J., S. Wagner, and F. J. DeGraves. 2003. Mastitis therapy and pharmacology. Vet. Clin. North Am. Food Anim. Pract. 19:109-138.

Farley, C., and A. E. Raftery. 2000. Model-based clustering, discriminant analysis, and density estimation. Technical Report No. 380. University of Washington, Seattle.

Farley, C., and A. E. Raftery. 2002. MCLUST: Software for modelbased clustering, density estimation and discriminant analysis. Technical Report No. 415. University of Washington, Seattle.

Fetrow, J., S. Stewart, S. Eicker, R. Farnsworth, and R. Bey. 2000. Mastitis: An economic consideration. Pages 3-47 in Proc. 39th Annu. Mtg. Natl. Mastitis Council. Natl. Mastitis Counc., Inc., Madison, WI.

Gonzalez, R. N., D. E. Jasper, N. C. Kronlund, T. B. Farver, J. S. Cullor, R. B. Bushnell, and J. D. Dellinger. 1990. Clinical mastitis in two California dairy herds participating in contagious mastitis control programs. J. Dairy Sci. 73:648-660.

Hillerton, J. E., and E. A. Berry. 2003. The management and treatment of environmental streptococcal mastitis. Vet. Clin. North Am. Food Anim. Pract. 19:157-169.

Hogan, J. S., R. N. Gonzalez, R. J. Harmon, S. C. Nickerson, S. P. Oliver, J. W. Pankey, and K. L. Smith. 1999. Streptococcus species. Pages 43-63 in Laboratory Handbook on Bovine Mastitis. Natl. Mastitis Counc., Inc., Madison, WI.

Hogan, J. S., and K. L. Smith. 2003. Environmental streptococcal mastitis: Facts, fables, and fallacies. Pages 162-171 in Proc. 42nd Annu. Mtg. Natl. Mastitis Counc., Orlando, FL. Natl. Mastitis Counc., Inc., Madison, WI.

Hogan, J. S., K. L. Smith, K. H. Hoblet, P. S. Schoenberger, D. A Todhunter, W. D. Hueston, D. E. Pritchard, C. L. Bowman, L. E. Heider, B. L. Brochett, and H. R. Conrad. 1989. Field survey of clinical mastitis in low somatic cell count herds. J. Dairy Sci. 72:1547-1556.

Morin, D., C. Mallard, P. Constable, R. Erskine, L. Fox, W. Hurley, J. Roberson, and L. Timms. 2001b. Effects of environmental streptococcus mastitis in six US dairy herds. Pages 155-159 in Proc. 2nd Int. Symp. Mastitis Milk Qual., Vancouver, B. C., Canada. Natl. Mastitis Counc., Inc., Madison, WI.

Morin, D., C. Mallard, L. Fox, J. Roberson, L. Timms, R. Erskine, W. Hurlely, and P. Constable. 2001a. Environmental streptococcal mastitis-Findings of a multi-state study. Pages 135-142 in Proc. 40th Annu. Mtg. Natl. Mastitis Counc., Reno, NV. Natl. Mastitis Counc., Inc., Madison, WI.

National Committee for Clinical Laboratory Standards (NCCLS). 2000. Performance standards for antimicrobial disk and dilution susceptibility tests for bacteria isolated from animals. Approved standards document M31-A. NCCLS, Wayne, PA.

Rossitto, R. V., L. Ruiz, Y. Kikuchi, K. Glenn, K. Luis, J. L. Watts, and J. S. Cullor. 2002. Antibiotic susceptibility patterns for environmental Streptococcus species isolated from bovine mastitis in central California dairies. J. Dairy Sci. 85:132-138.

Ruegg, P. L. 2003. Investigation of mastitis problems on farms. Vet. Clin. North Am. Food Anim. Pract. 19:47-73.

Schukken,Y. H., F. J. Grommers, D. van de Geer, and A. Brand. 1989 Incidence of clinical mastitis on farms with low somatic cell counts in bulk milk. Vet. Rec. 125:60-63.

Wolfgang, D. R., B. M. Jayarao, S. R. Pillai, A. A. Sawart, C. M. Burns, and L. J. Hutchinson. 2001. Farm management practices that influence the number and type of Streptococcus species and Streptococcus species-like organisms in dairy herds. Pages 286290 in Proc. 2nd Int. Symp. Mastitis Milk Qual., Vancouver, BC, Canada. Natl. Mastitis Counc., Inc., Madison, WI.

Zadoks, R., B. Gillespie, O. Sampimon, H. Barkema, S. Oliver, and Y. Schukken. 2001. Clinical, epidemiological and molecular characteristics of Streptococcus uberis. Pages 83-87 in Proc. 2nd Int. Symp. Mastitis Milk Qual., Vancouver, BC, Canada. Natl. Mastitis Counc., Inc., Madison, WI. 